\title{
The greatest soda-water lake in the world and how it is influenced by climatic change
}

\author{
M. Kadıŏlu, Z. Şen and E. Batur \\ Istanbul Technical University, Meteorology Department, Hydrometeorology Research Group, Maslak 80626 Istanbul, Turkey
}

Received: 10 December 1996 / Revised: 30 April 1997 / Accepted: 12 May 1997

\begin{abstract}
Global warming resulting from increasing greenhouse gases in the atmosphere and the local climate changes that follow affect local hydrospheric and biospheric environments. These include lakes that serve surrounding populations as a fresh water resource or provide regional navigation. Although there may well be steady water-quality alterations in the lakes with time, many of these are very much climate-change dependent. During cool and wet periods, there may be water-level rises that may cause economic losses to agriculture and human activities along the lake shores. Such rises become nuisances especially in the case of shoreline settlements and low-lying agricultural land. Lake Van, in eastern Turkey currently faces such problems due to water-level rises. The lake is unique for at least two reasons. First, it is a closed basin with no natural or artificial outlet and second, its waters contain high concentrations of soda which prevent the use of its water as a drinking or agricultural water source. Consequently, the water level fluctuations are entirely dependent on the natural variability of the hydrological cycle and any climatic change affects the drainage basin. In the past, the lake-level fluctuations appear to have been rather systematic and unrepresentable by mathematical equations. Herein, monthly polygonal climate diagrams are constructed to show the relation between lake level and some meteorological variables, as indications of significant and possible climatic changes. This procedure is applied to Lake Van, eastern Turkey, and relevant interpretations are presented.
\end{abstract}

\section{Introduction}

Lakes are natural water storage reservoirs whose basins have evolved as a result of past geological activities. In many areas, they constitute significant fresh water reserves, accounting for about $26 \%$ of the global fresh water resources. Elsewhere lakes are too saline to be used for supply. According to Gleick (1993), the total volume of fresh water in the world's lakes is about $91 \times 10^{3} \mathrm{~km}^{3}$; that of saline water is $85 \times 10^{3} \mathrm{~km}^{3}$.

Unfortunately, in some parts of the world, unplanned urban areas have developed along lake shores without consideration of the possible future rates in level rises. Lake Van, in the eastern part of the Anatolian peninsula, Turkey, exemplifies one such case. A water level rise of $2 \mathrm{~m}$ during the last 10 years and its consequences have provided a salutary lesson to administrators, local governmental authorities, people and researchers alike. There are two aspects to the problem, namely, its identification and its solution. At the identification stage, it is necessary to evaluate possible explanations for the water level rise. Among the present explanations are many theories such as the sedimentation in the lake, geotectonic movements, sun spot and climate change effect (Kadıoglu, 1995). Most of these are rather speculative without convincing scientific evidence.

This study proposes that the recent-lake level rises are due to meteorological variability. A digression is made from traditional methodology in that possible trends in water level rises are sought neither in the arithmetic averages nor in the meteorological historical lake level time series analysis, but in the average standard deviation from monthly climate polygons.

\section{Location and climatic features}

The world's largest soda lake, Lake Van, is situated on the eastern Anatolian high plateau of Turkey at about $43^{\circ} \mathrm{E}$ and $38.5^{\circ} \mathrm{N}$ (Fig. 1). At this latitude, winter is very severe with temperatures frequently under $0{ }^{\circ} \mathrm{C}$ during at least three months of the year. Most of the precipitation in the lake drainage basin falls during the winter season, as snow and as a rainy season in late spring. Precipitation is low over the rest of the year. Highest rates of runoff occur in the spring, following snow melt and heavy rain, with the greatest amounts in May of each year. On average, the discharge to the lake in the spring period amounts to almost $80 \%$ of the water 


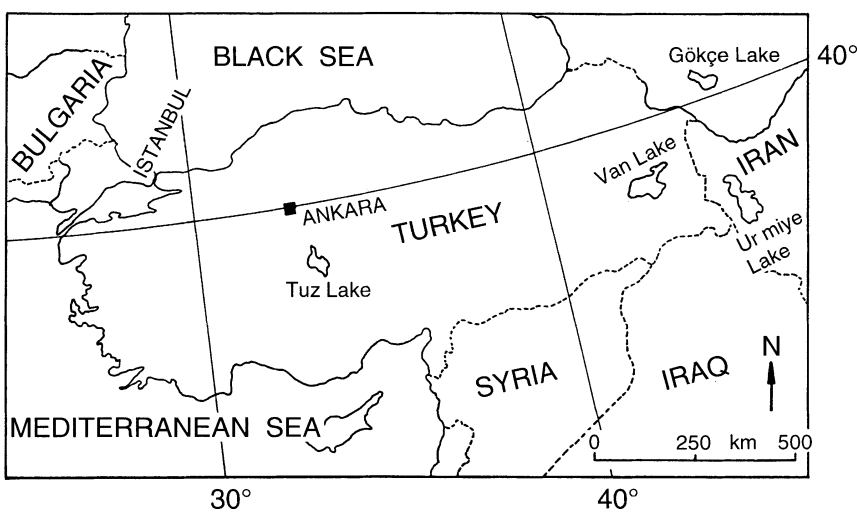

Fig. 1. Location map

volume. The period from July to September is the warmest and driest with average temperatures of $20^{\circ} \mathrm{C}$. The average range of diurnal temperature variations is about $20{ }^{\circ} \mathrm{C}$. The average extent of the lake is $3600 \mathrm{~km}^{2}$ (Kempe et al., 1978). It is surrounded by a relatively large drainage basin of $12500 \mathrm{~km}^{2}$ with the Bendimahi and Zilan rivers (Fig. 2) being the most important. The average elevation of the lake is $1650 \mathrm{~m}$ above mean sea level. It is surrounded by hills and mountains, some of which have elevations well above $4000 \mathrm{~m}$. The lake does not have any natural outlet and, hence, it gathers surface water from all around the lake. With these properties the Lake Van constitutes the world's fourth largest closed basin lake with a volume about $600 \mathrm{~km}^{3}$. It has been calculated that annually $4.2 \mathrm{~km}^{3}$ of water is lost to the atmosphere by evaporation. This is balanced by the long-term averages of annual surface runoff and precipitation respectively of $1.7 \mathrm{~km}^{3}$ and $2.5 \mathrm{~km}^{3}$.

In general, within-year water fluctuations have a pronounced increment starting from January and ending in June with a decline in the water level. However, over recent years, such fluctuations have been observed to have been increasing interannually as is obvious from the record in Fig. 3, covering the period 1944-1994. In this figure, the vertical axis indicates the readings on a staff gauge located at the Tatvan discharge measurement station. As is also obvious, the lake level increases rather rapidly from 1987 onwards. Although the long-range average of the lake level is at $1648 \mathrm{~m}$ above the mean sea level, it has reached $1650 \mathrm{~m}$ with a $2 \mathrm{~m}$ rise. Conse-

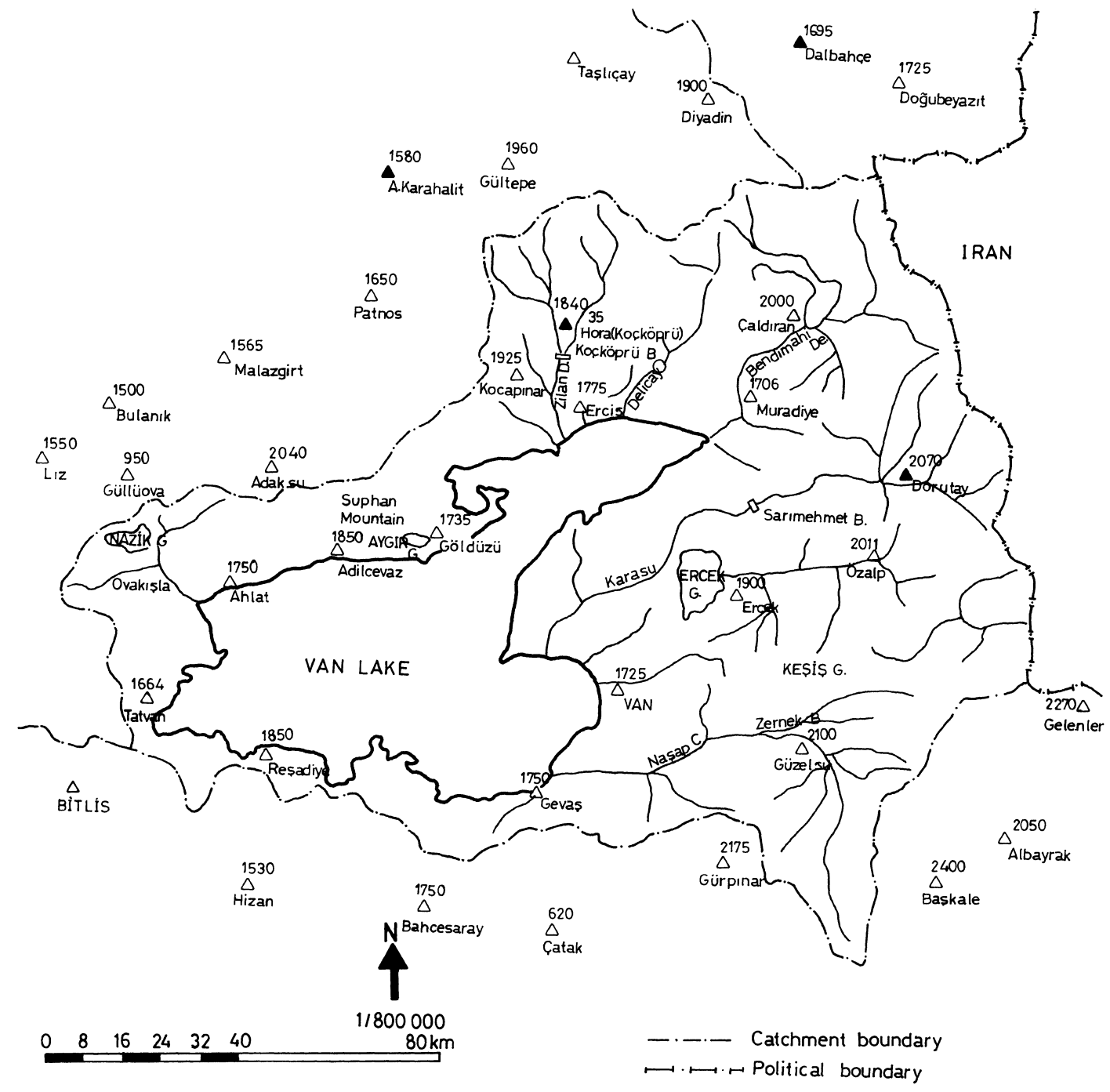

Fig. 2. Lake Van drainage basin 


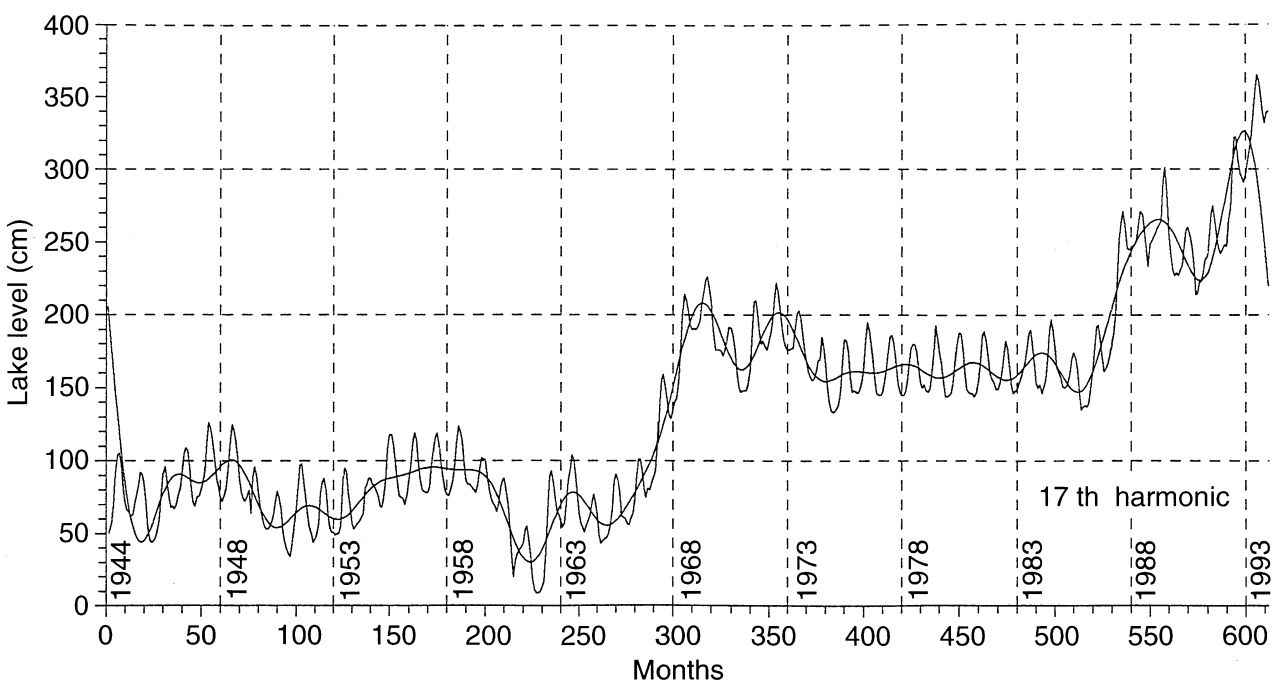

Fig. 3. Van Lake level fluctuation record from 1944 to 1994 quently, much usable land along the lake shore has been in undulated, except where it was protected by defensive levees. However, even these levees have now been overspilled. Flood water circumvents the levees from the unprotected lowlands. Under normal climatic conditions, the lake water level fluctuations have yearly amplitudes of between $40-60 \mathrm{~cm}$ at the most. In fact, the lake level average amplitude was calculated by Degens and Kurtman (1978) for 29 years of record between 1944-1974 annually as about $49.7 \pm 18 \mathrm{~cm}$ with a standard deviation of $18.5 \mathrm{~cm}$. However, the record in Fig. 3 has average and standard deviation values of $136.8 \mathrm{~cm}$ and $70.8 \mathrm{~cm}$, respectively. These indicate average percentage increases of 275 and 383 in the mean lake level and in the fluctuations amplitude, respectively. They show clearly that for some reason the averages of the mean and standard deviations have increased greatly. Such increases are attributed to climatic variations in the catchment area. This has become more humid, implying more precipitation and less evaporation. A similar interpretation suggests that there have been cooler seasons with wet periods of increased precipitation. During normal annual fluctuations, the lake loses and gains about $1.5 \%$ of its total water volume.

Lake Van had also experienced level increases in late 1880s, when Sieger (1888) reviewed various explanation for the level fluctuations. According to his study, the level fluctuations were in the order of few meters. Because there were no climatic data he could not relate this fluctuation to any external phenomena.

Sun-spot activity was considered by Kempe et al., (1978) as a possible cause of level change. During this period, the lake behaved in a normal manner in that there were no significantly abnormal years which could affect the hydrological or climatological balances. They tried to relate the level fluctuations to the annual number of sun-spots. During normal years, there was a close agreement between these two variables, as shown in Fig. 4. Both curves have a frequency of about 11 years. This suggests that the solar activity influences the overall water balance of Lake Van during normal years. It has also been observed that an increased activity is followed by an increase in the water level of the lake with a delay of about one year. Such an increase in the sun-spot activity probably leads to unstable weather conditions, and consequently greater cloud cover would have brought more precipitation and lower evaporation rates, because the climate was more humid.

However, it is noticeable from Fig. 4 that towards the end of the period they deviate from each other, indicating that the lake level change was no longer dependent on the number of sun-spots but some other effects which are considered in this study as the climate change related events.

\section{Geological setup}

According to Blumenthal et al., (1964) extensive volcanic eruptions took place in the eastern parts of Turkey during the Late Pleistocene. This volcanic area extends about $230 \mathrm{~km}$ along a northeast-southwest trending line, ending in the southwestern point with the Nemrut volcanic mountain. Another volcanic mountain, Süphan, is located to the north of the lake. Its last eruption took place in 1441 according to the record in the sediments of the lake. Present-day activity is confined to

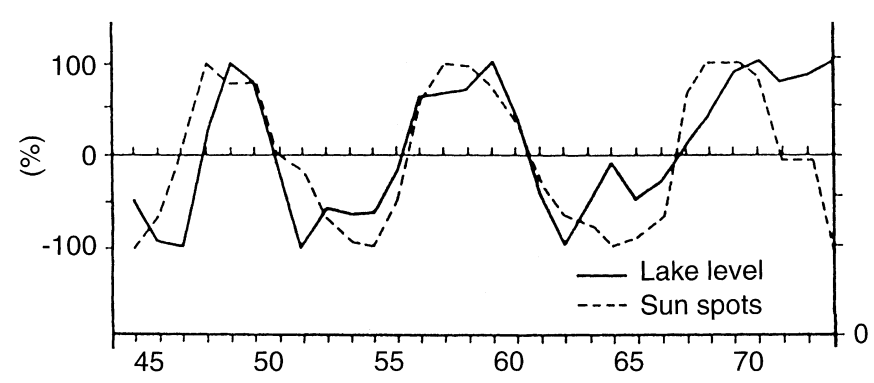

Fig. 4. Lake level relationship to number of sun-spots during 1944 1974 period 
hot springs. The lake level rose rapidly after the northeast-southwest trending fluvial system was dammed and the water impoundment began.

Lake Van has been formed by the damming of the fluvial system by debris that came from the Nemrut volcanic eruptions. The water has been impounded behind this natural dam and formed the present-day lake. Initially, the lake level increased very rapidly and progressively. A water balance was reached between the total inflow in forms of direct rainfall on the lake surface and delayed surface runoff from the surrounding drainage basin, due to evaporation losses. After balance was achieved, water level fluctuation depended on the annual climatic fluctuations. In such a closed system, dramatic water level changes take place only if the imbalances occur as a result of changing climatic conditions. During past geological times slow, steady or episodic lake level drops must have accompanied the subsidence of the Tatvan Basin (Wong and Finckh, 1978). After a balance had been struck, lake level fluctuations would have occurred in response to two major factors. One of these was rather rapid, due to climatic changes and the shape change of the basin, and the second one was a rather gradual subsidence, due to the steep boundary faults and the deep-lying basement over which the sedimentation accumulates.

The impounded water in Lake Van is very alkaline with $\mathrm{pH}$ values well over 9 and it contains considerably more potassium, lithium and sodium than sea water. It is the greatest soda lake in the world with the sum of bicarbonate and carbonate ion contents slightly greater than chloride content. Carbonate contents are 100 times richer than oceanic sea water (Kempe et al., 1978).

\section{Monthly climate polygons}

In general, these are defined as the scatter diagram for 12-monthly averages of two hydrometeorological variables on a Cartesian coordinate system. The 12 points are connected sequentially by straight lines which then form a polygon. The general appearance of such a polygon, its successive sides and corners summarize monthly climate change information about within-year behavior over long periods. Monthly lake levels are considered in relation to other meaningful meteorological variables through these climate polygons.

In order to show the patterns of lake level fluctuations, their monthly averages are plotted against the major hydrometeorological variables as shown in Figs. 5-10. Each one of these figures shows a closed polygon indicating the within-year average balance. Their interpretation gives clues about the lake level fluctuations' dependence on these variables. The following interpretations come from lake level-relative humidity polygonal diagrams in Fig. 5.

a. In general, lake level increases with decreasing relative humidity starting from January until June. During this period the effect of humidity is rather insignificant initially from January to March but the steepest lake level increases occur during April-May especially in Fig. 5a. On the other hand, there is lake level decrease during June-December monthly period.

b. Comparison of 1944-1968 and 1969-1994 annual periods shows clearly that although the within-year pattern remains the same but interannually lake level increased on the average by $1-1.2 \mathrm{~m}$. This is tantamount to saying that there is a steady increase in the lake level. The two polygons do not overlap and therefore, there is implication of climate change in the region.

c. The maximum lake level occurs in June and the minimum levels are during November-December period.

d. From December onwards although there is no significant change virtually in the relative humidity the lake level increases rather rapidly. The reason of level increase during this period should be sought outside the relative humidity.

e. Starting from March onwards the relative humidity decreases but the lake level increases steadily almost linearly, (see Fig. 5b).

f. After June although the decrease in the relative humidity continues until the end of August the lake level starts to decline.
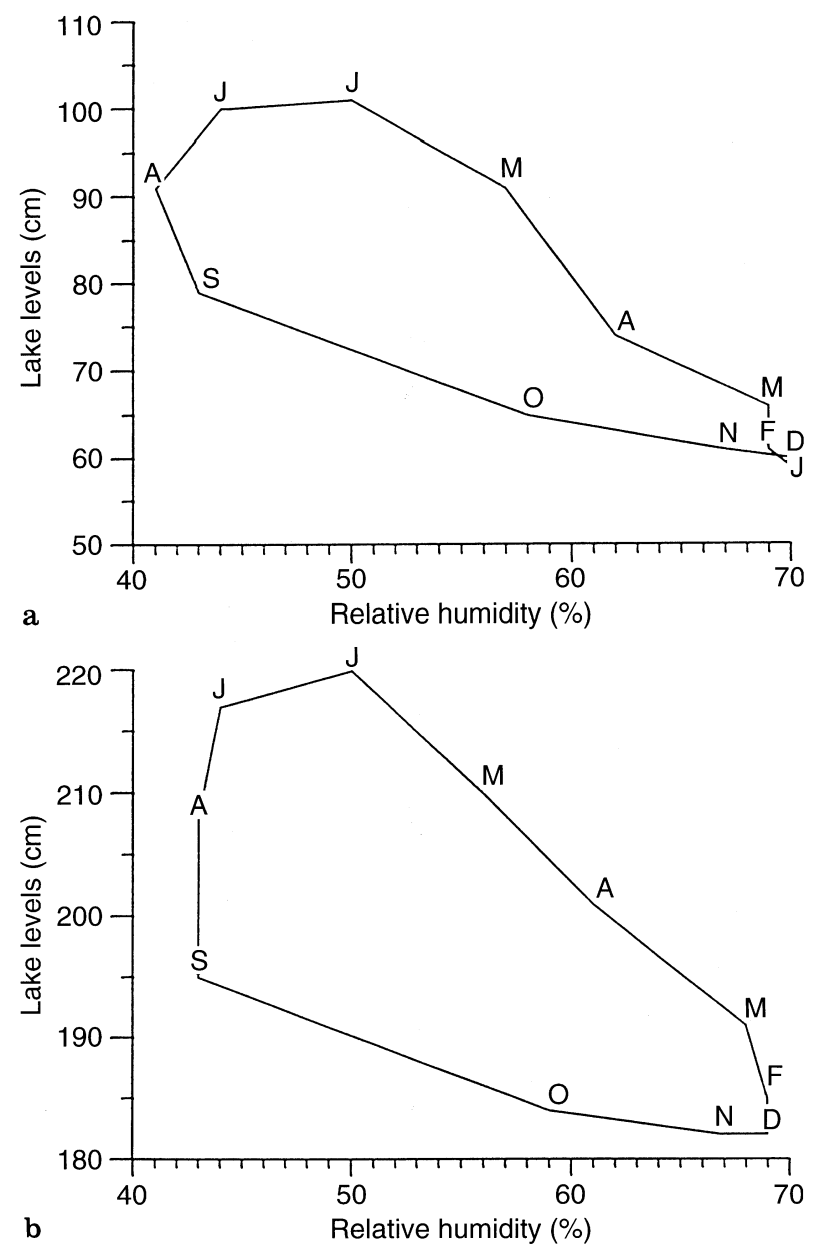

Fig. 5a, b. Lake level-relative humidity polygons a 1944-1968 period, b 1969-1994 period 


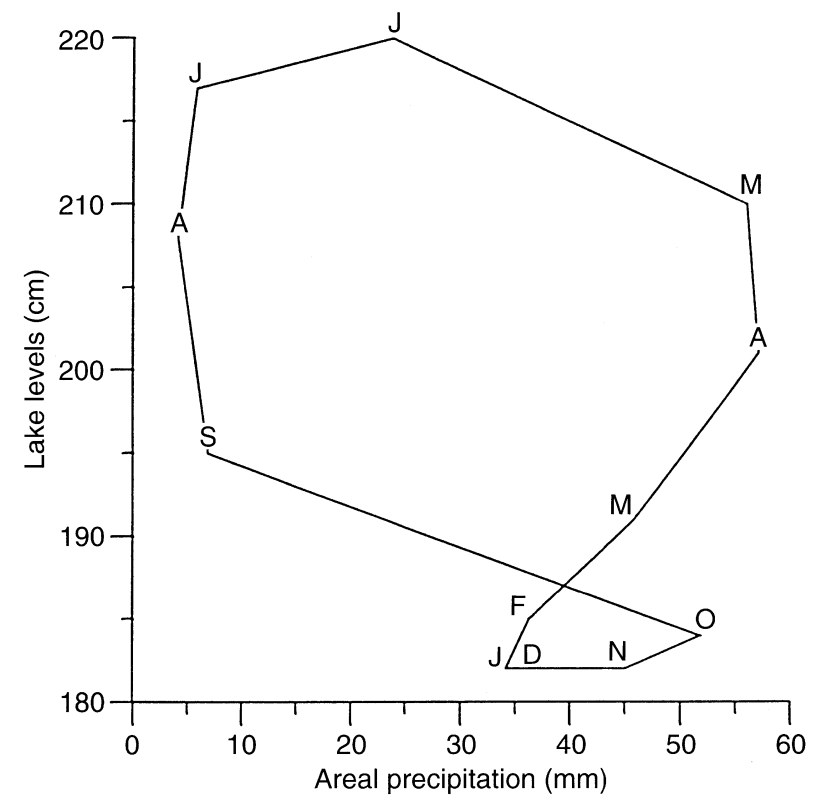

Fig. 6. Lake level-areal precipitation polygon

g. Increase in the relative humidity starts at a slow rate after August coupled with steep decrease in the lake water level. However, from September to November there is steady decrease both in lake level and the relative humidity.

Figure 6 shows monthly lake level changes with mean monthly areal precipitation. At first glance this diagram has two adjacent polygons compared to the levelhumidity polygon in Fig. 5. The general features of this polygonal diagram are as follows:

a. From January until the end of April increase in areal precipitation causes lake level increases in rather high rates. This is a direct consequence of rainfall transformation into runoff that contributes to the lake storage.

b. After April until August the precipitation decreases continuously but during this period the water level continues to rise until June because of delayed contribution from the runoff and then with the diminishing runoff contributions the level starts to drop until the end of August.

c. The wet period starts in September and continues till the end of October then snowfall takes place causing an overall decrease in the areal precipitation because the snowmelt does not occur until later.

Furthermore, as a representation of local precipitation, the average monthly values in Tatvan station are indicated in Fig. 7 with the lake level fluctuation for two consecutive periods of 1944-1968 and 1969-1994. In general, these two polygons have the same monthly pattern but interannually they occur at two different levels. There is almost $125 \mathrm{~cm}$ difference in level between the two polygons. The polygon in the later period, i.e., Fig. $7 b$ has a wider vertical width which implies that during this period the water level changes were comparatively more rapid.

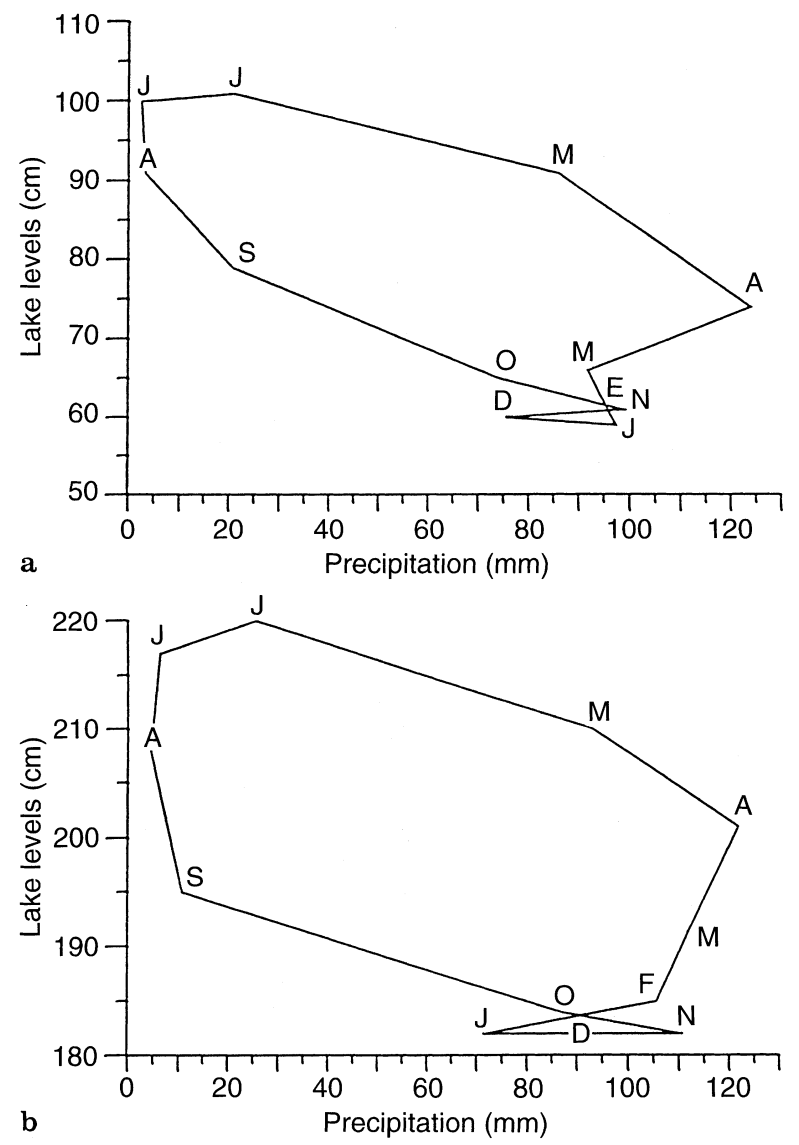

Fig. 7a, b. Lake level-Tatvan precipitation polygon a 1944-1968 period, b 1969-1994 period

Evaporation polygons in Fig. 8 indicate opposite general trends to the humidity and precipitation polygons in that during the January-June period, increase in evaporation causes lake level increases. The reason for such an increase is due to relatively small rates of evaporation which cannot cancel out the runoff and direct precipitation contributions to the lake. However, the July-December limbs of some polygons show a decrease in the evaporation rate coupled with lake level decrease. Initially the level decrease is rather sharp but with time, it decreases at slower rates. Again the thickness of polygon in Fig. 8b implies significantly more water level fluctuation during the recent period.

Lake level fluctuation-sun spot number polygons in Fig. 9 indicate clearly that during the $1944-1968$ period there is a significant relationship between the two variables on a monthly basis. However, in a more recent period (1968-1994) the general appearance of the polygon is almost vertical on the average around 90 sunspot number which means that the changes in the lake levels are independent of the sunspot numbers. This is tantamount to saying that in the second period the lake level changes are more dependent on the local climatic change and hence hydrologic cycle rather than the effects from space.

Finally, runoff polygons in Fig. 10 at two different locations, on the Süfrezar and Bendimahi streams, have 

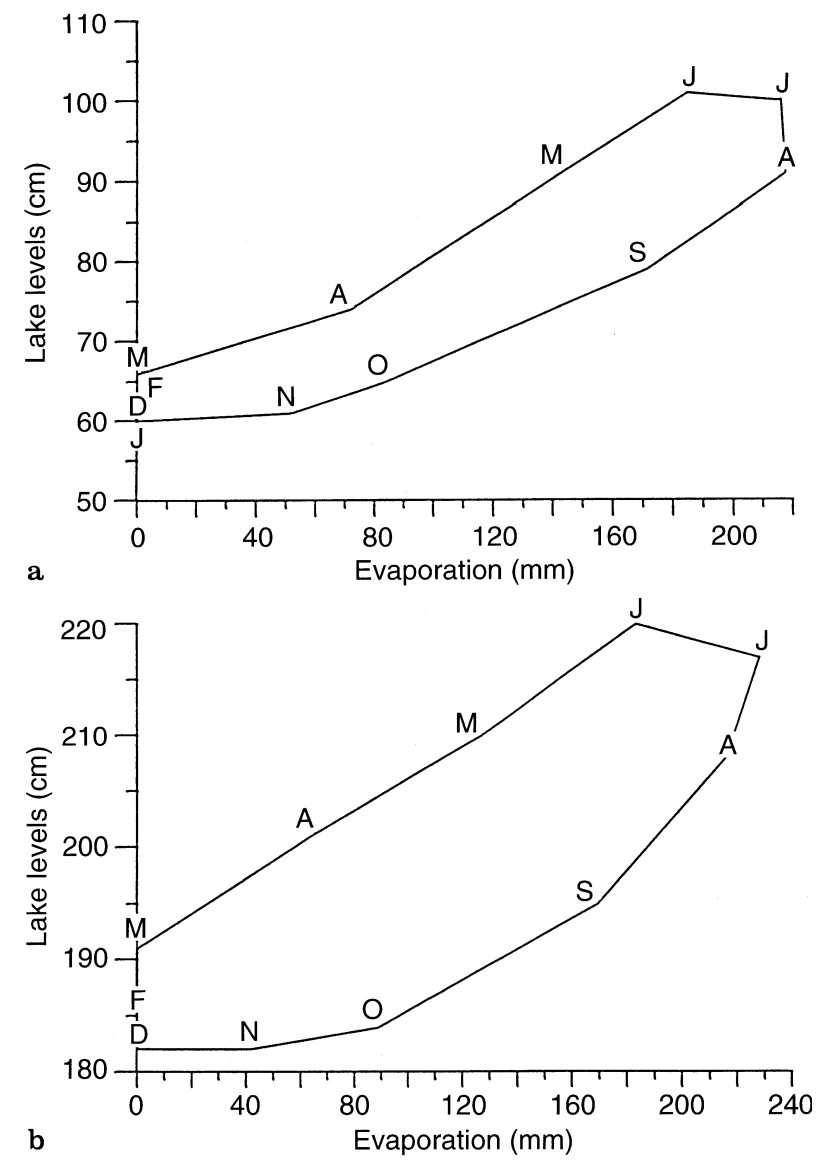

Fig. 8a, b. Lake level-evaporation polygons a 1944-1968 period, b 1969-1994 period

more or less similar trends in that a sharp increase in runoff from February onwards until the end of April causes an increase in the lake level but after April increases in lake level occur with decreasing runoff. In both runoff polygons sharp decreases start to occur from June onwards with no significant change in the runoff volume.

Table 1 summarizes the trends in the climate polygons on a bimonthly basis. In the interpretation of arrows in the Table 1 it must be remembered that the
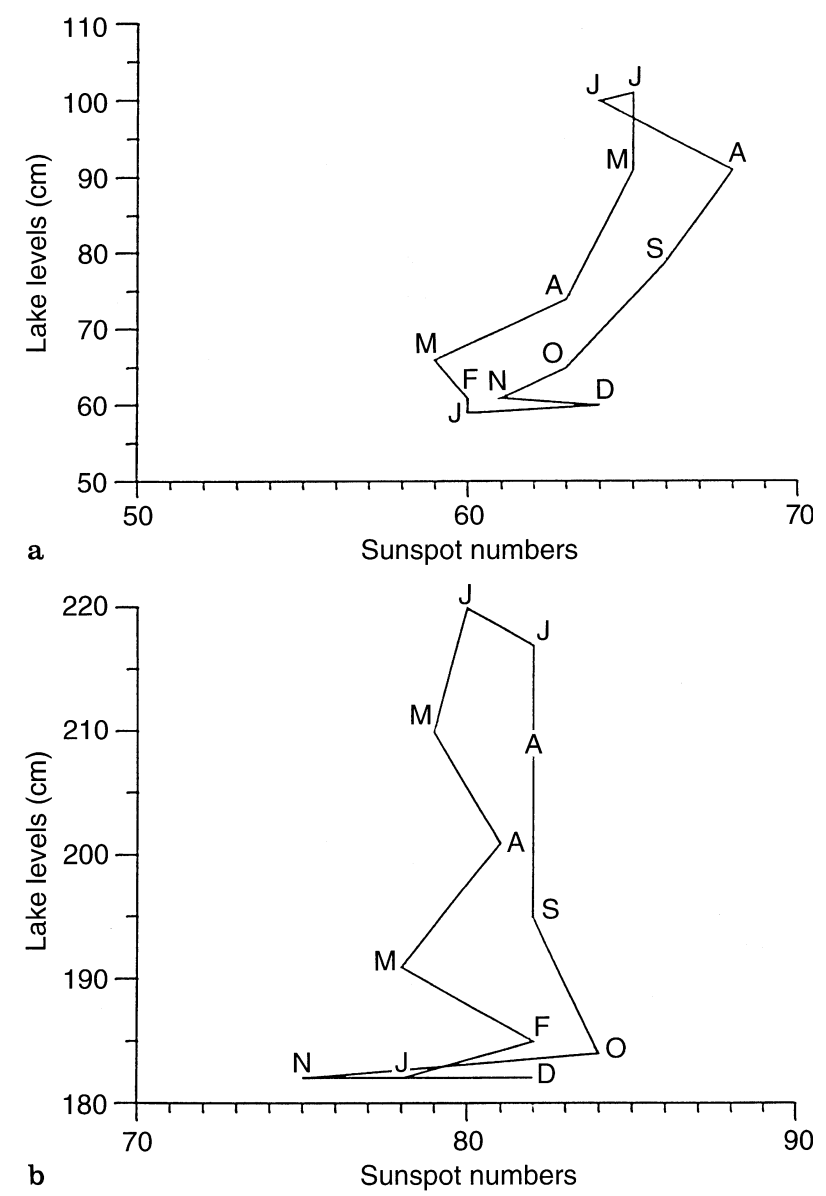

Fig. 9a, b. Lake level-sun spot number polygons a 1944-1968 period, b 1969-1994 period

lake water level fluctuations are on the vertical axis and the hydrometeorological variables are on the horizontal axis. For instance, in order to deduce the effect of each hydrometeorological variable on the lake level in JuneAugust column 8 must be considered against each of the variables in turn. Average decreases coincide with decreases in the relative humidity, areal precipitation and evaporation, runoff has no effect and sunspot number increases cause a decrease. Each polygon may be interpreted in detail.

Table 1. Lake level fluctuations relationship to various hydrometeorological variables

\begin{tabular}{|c|c|c|c|c|c|c|c|c|c|c|c|c|}
\hline $\begin{array}{c}\text { Variable } \\
\text { (1) }\end{array}$ & $\begin{array}{l}J-F \\
(2)\end{array}$ & $\begin{array}{l}\text { F-M } \\
(3)\end{array}$ & $\begin{array}{l}\text { M-A } \\
(4) \\
\end{array}$ & $\begin{array}{c}\text { A-M } \\
(5)\end{array}$ & $\begin{array}{l}\text { M-J } \\
(6) \\
\end{array}$ & $\begin{array}{l}\mathrm{J}-\mathrm{J} \\
(7) \\
\end{array}$ & $\begin{array}{l}\mathrm{J}-\mathrm{A} \\
(8) \\
\end{array}$ & $\begin{array}{l}\text { A-S } \\
(9) \\
\end{array}$ & $\begin{array}{l}\text { S-O } \\
(10) \\
\end{array}$ & $\begin{array}{l}\mathrm{O}-\mathrm{N} \\
(11) \\
\end{array}$ & $\begin{array}{l}\text { N-D } \\
(12) \\
\end{array}$ & $\begin{array}{l}\text { D-J } \\
\text { (13) } \\
\end{array}$ \\
\hline Relative humidity & $\uparrow$ & $\uparrow$ & $\kappa$ & $\boldsymbol{\kappa}$ & $\kappa$ & $k$ & $k$ & $y$ & $y$ & $y$ & $\rightarrow$ & $\uparrow$ \\
\hline Areal precipitation & $\pi$ & $\pi$ & $\pi$ & $\kappa$ & $\kappa$ & $k$ & $k$ & ע & ע & $k$ & $\leftarrow$ & $\leftarrow$ \\
\hline Runoff & $\kappa$ & $\pi$ & $\pi$ & $\kappa$ & $\kappa$ & $k$ & $\downarrow$ & $k$ & $y$ & $y$ & $\rightarrow$ & $\leftarrow$ \\
\hline Evaporation & $\uparrow$ & $\uparrow$ & $\pi$ & $\pi$ & $\pi$ & ע & $k$ & $k$ & $k$ & $k$ & $\leftarrow$ & $\uparrow$ \\
\hline Sunspot & $\lambda$ & $\kappa$ & $\pi$ & $\kappa$ & $\pi$ & $y$ & $y$ & $k$ & $k$ & $k$ & $\rightarrow$ & $\leftarrow$ \\
\hline
\end{tabular}



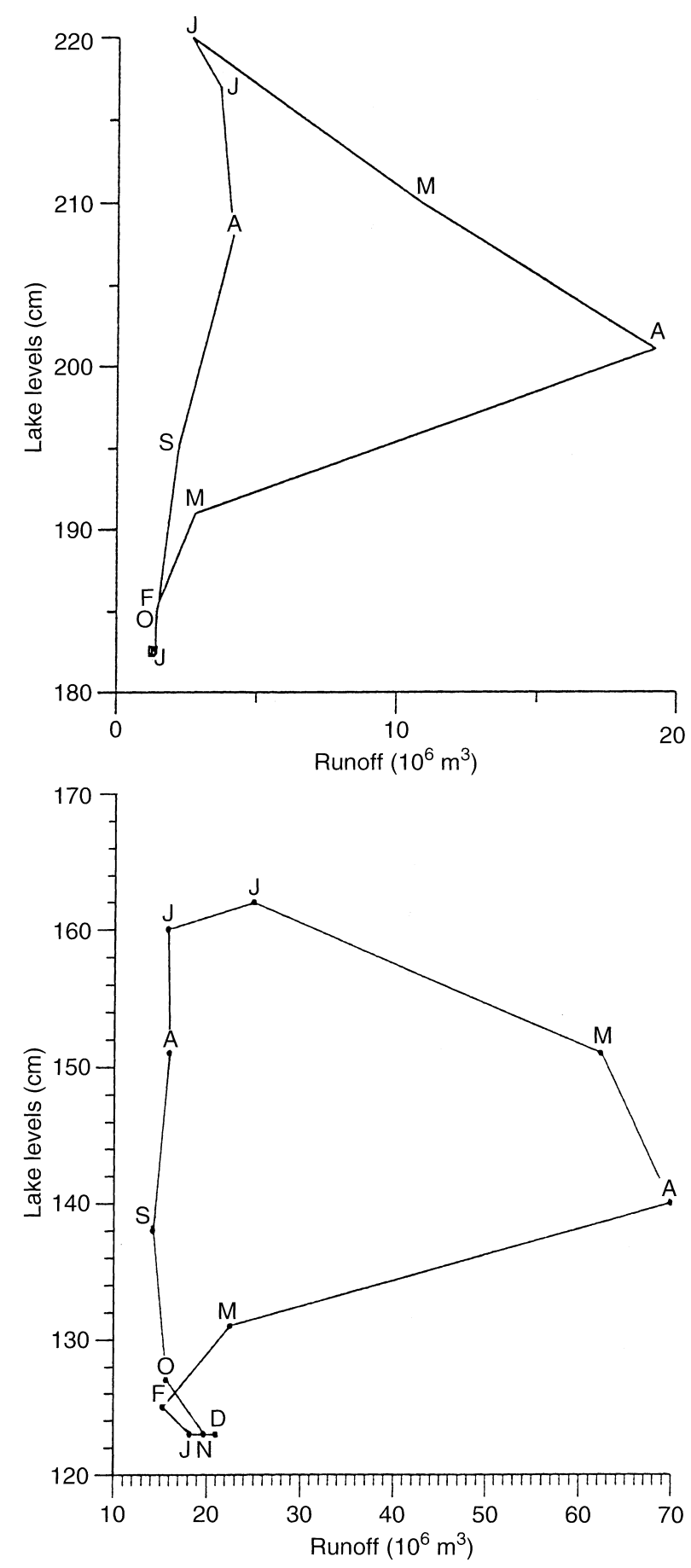

Fig. 10a, b. Lake level-local runoff polygons a Süfrezor, b Bendimahi

\section{Average standard deviations of water level fluctuations}

The basic information about long-term fluctuation of lake level water are the past records at a set of given locations. These indicate many irregular and rather random ups and downs in the observed extreme values. The irregularity and random pattern can be modeled as averages but the episodes of the water level increase or decrease as well as the extreme values in the future are all expected to exceed the recorded values in the past.
Hence, in modeling the water highs and lows, not just the extreme values are needed but also the episodes must be carefully examined and modeled. It is outside this study's scope to model these features. However, qualitative accounts will be presented here.

Here, the series of precipitation records and their relationships to the lake water level records will be investigated statistically leading to scientific evidence about the significance of the climate change in the water level fluctuations within the study area. Lake Van provides a unique opportunity to study the climate change effect because its water is not regulated by human intervention and there are no normal outlets. Hence, the water balance in the lake is governed entirely by natural phenomena like climate change and local hydrological effects. Such a fortunate situation arises because of the unsuitable quality of water for irrigation or water supply purposes. Besides, deep lakes such as Van and its inland sea margins provide researchers such as hydrometeorologists, hydrologists and geologists with a unique opportunity to study the climatic fluctuations in the very recent or geological past.

The major influences on water level fluctuations in such a closed basin lake are contributed by the following factors.

a. The geomorphological features of the drainage basin, size and shape of the lake itself.

b. Hydrologic elements such as the surface and river runoff toward the lake.

c. Climatic elements over the region including especially the precipitation records and to some extent evaporation and temperature.

The interaction of these different factors make up the water level fluctuation scenario of the Lake Van. In fact, these factors do not only control the water level changes but additionally the water quality changes, dissolved and sediment load of rivers and their biological populations, though all of these are outside the scope of this study. A detailed account about these is provided by Degens and Kurtman (1978).

Monthly water level fluctuations from 1944 to 1994 are shown in Fig. 3. This time series of lake levels is filtered through Fourier analysis and hence the general trend is also shown on the same figure. A close inspection indicates that there are abnormal water rises during years 1968-1969 and, again when the present-day trend starts, from 1986 onwards. It is possible to make simple mathematical models for these fluctuations by detrending the whole fluctuation into deterministic and stochastic parts. So far, in all researches the averages of different types either as stated through Fourier analysis (Batur, 1996) or various order of moving average procedures are used in the literature. However, a digression is adopted here in that the average standard deviation variations with time are analyzed by applying moving averages of various orders. The main reason for the adaptation of the average standard deviation variation is due to the fact that arithmetic averages do not provide meaningful information about the long-term fluctuations but the departures from long-term averages 
contribute directly to the water level fluctuations. Besides the amplitude of the fluctuations is related to the standard deviation directly. Standard-deviation, by definition, shows the average deviations about the mean water level. Figures 11-13 indicate 3-, 6- and 12-monthly moving averages of the lake level fluctuation standard deviations. Moving averages of 3-, 6- and 12-monthly orders are chosen to show the seasonal, half-yearly and annual standard deviation variation patterns. Interpretation of these figures leads to the following significant results.

a. The standard-deviation fluctuations are rather haphazard which implies inconsistency in their time

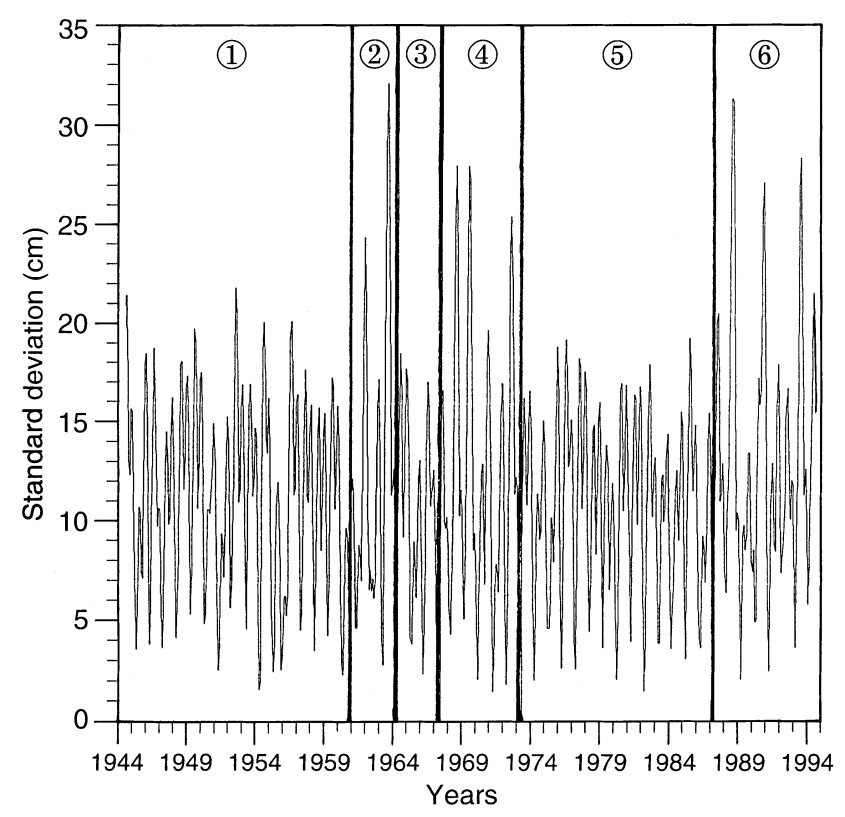

Fig. 11. Six monthly moving averages of the standard deviation

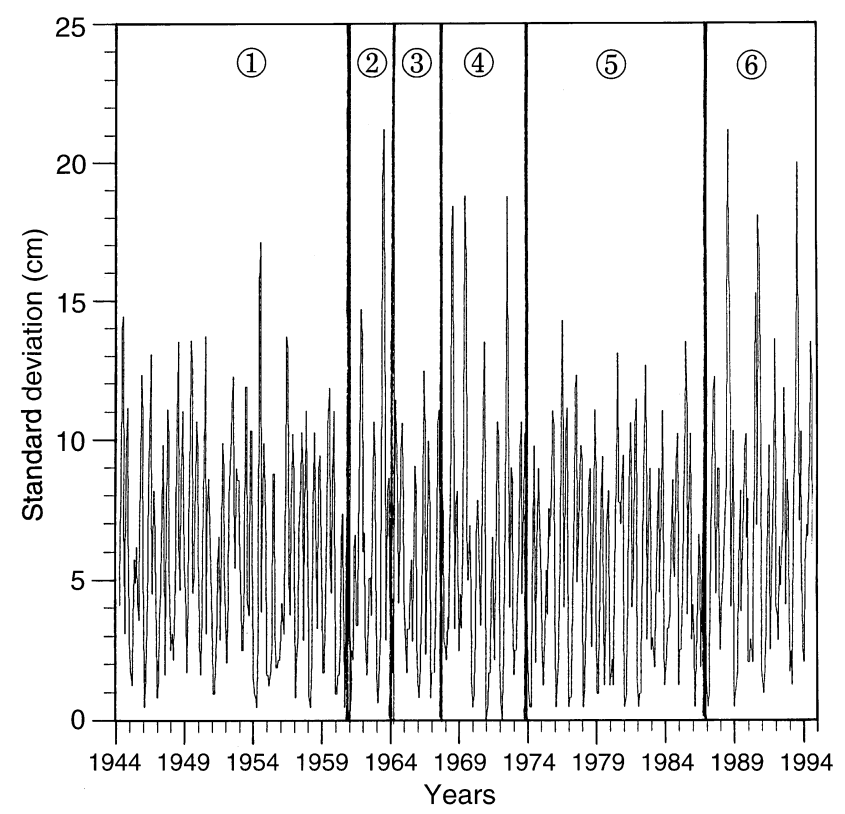

Fig. 12. Three monthly moving averages of the standard deviation

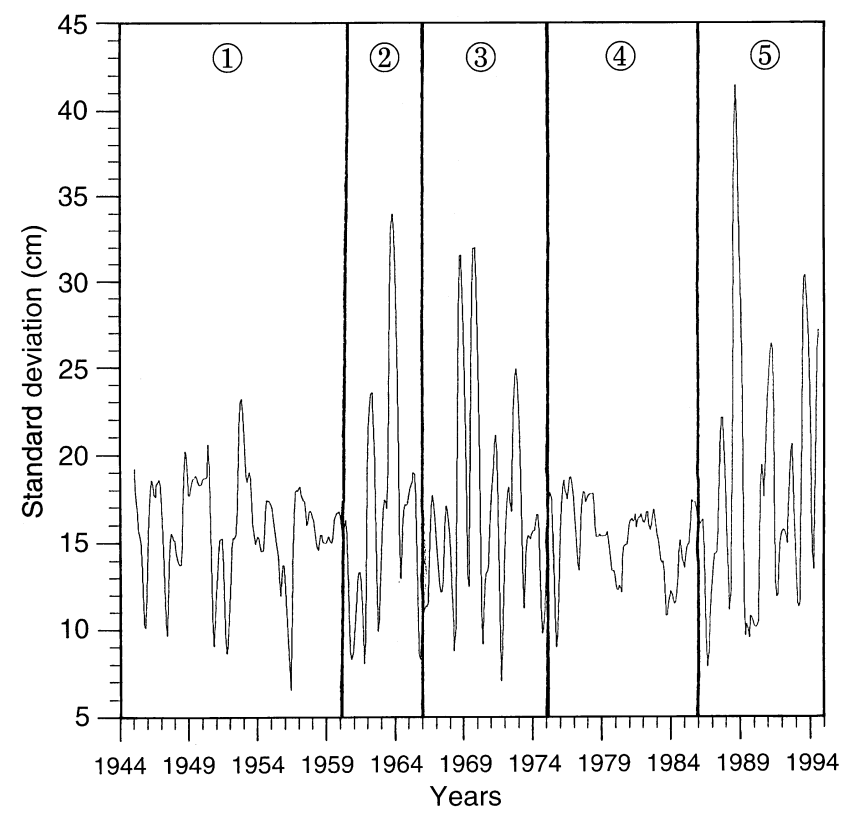

Fig. 13. Twelve monthly moving averages of the standard deviation

variations. Such a non-deterministic variation means that the weather events in the area are rather unstable.

b. Standard deviations greater than the overall period standard deviations are more abundant than the below-average standard deviations. Extreme standard deviations are clustered in certain periods. For instance, in Fig. 12, six time zonations are distinctively apparent. First, third and fifth zones are the normal periods during which ups and downs have almost the same magnitude, but in the other three zones, abnormal standard deviations extend over the whole record standard deviation. As the moving-average order increases these normal and abnormal zones become more clear and obvious.

c. In Fig. 13, there is initially a very slightly decreasing trend in the first zone which is followed by the disturbance during the second zone because the standard-deviation fluctuation is comparatively very pronounced. In the last zone, there is a steadily increasing trend in addition to there being the highest standard deviation records within this zone.

\section{Simple suggestions for solution}

Lake Van is more than $1000 \mathrm{~m}$ above the mean sea level and it is located in the southern low-lying platforms from which the Tigris River flows southward. Such a great elevation brings to mind the possibility of hydroelectrical energy production by releasing the lake water down through an artificially constructed channel.

Such a solution will lead to deterioration in the river flow and it might be not suitable for irrigation purposes. In order to alleviate this situation Ölçgen (1995) 
suggested that the surface runoff from the major rivers that flow into Lake Van including the rivers Zilan, Deliçay and Bendimahi in the northeast, Karasu, Morali and Engil rivers in the east, Murdasu and Pepiçek in the north runoffs should be carried by light underwater pipes to a southern low-lying point on the lake shore. From there onwards by a diversion tunnel will provide a head of more than $1000 \mathrm{~m}$ for hydroelectric power generation. There are four-fold benefits from such a solution. First the generation of hydroelectric power for sale, second, the maintenance of water quality in the Tigris river, third, avoidance of Lake Van level fluctuations by controlling it through the underwater pipe-line net, and fourth, augmentation of the Tigris river runoff.

\section{Conclusions}

An historical account of Lake Van waterlevel fluctuations in the western province of Turkey is presented. This lake is the greatest soda water lake in the world and has a closed basin with no outlets. Within the last decade a steady water-level increase in the lake has caused some socioeconomical and irrigational problems along the lake shore-line. The lake-level fluctuations are related to three different effects of which the climate change over the whole lake drainage basin is the most critical. The other two effects, namely, sun-spot numberrelated lake-level fluctuations and sediment deposition at the bottom of the lake or the tectonic activities leading to subsidence in the lake level give rise to comparatively insignificant level changes. In particular, the geological alternative causes very slow and perhaps unappreciable level fluctuations, if any. However, sunspot number changes with an average period of about 10 to 11 years do give rise to level fluctuations of similar period. Abnormal, unexpected and disturbing lake-level changes occur due to climate change and global warming as a result of unstable weather activities. In this study, the climatic polygons that show the scatter diagrams of monthly average lake levels with various meteorological variables are obtained and the necessary general interpretations are presented.
All the classical lake-level change approaches are confined to past-level records and especially on their filtered forms, in order to avoid random fluctuations. Consequently, the interpretations are drawn on the average-level fluctuations. An entirely different view is taken if the standard deviation rather than the mean values play a definitive role in the explanation of abnormal level rises or falls. The past record is divided into subzones of time durations based on the filtered standard deviation fluctuations by using seasonal, halfannual and annual moving averages.

Acknowledgements. Topical Editor D. J. Webb thanks C. Reynolds for his help in evaluating this paper.

\section{References}

Batur, E., Van Gölünün Su Bütçesi ve Havza, Iklimi. Unpublished MSc Thesis, İstanbul Technical University, Meteorology Department, $124 \mathrm{pp}$ (in Turkish), 1996.

Blumental, M. M., V. D., Kaaden, and V. I., Vlodaveta, Catalogue of the active volcanoes of the world including solfatara fields. Part XVII Turkey and Caucasus. Int. Assoc. Volcanol, 23 pp, 1964.

Degens, E. T., and Kurtman, F., The geology of Lake Van. The Mineral Research and Exploration Institute of Turkey, Rep. 169, $158 \mathrm{pp}, 1978$.

Gleick, P. H., Water in Crisis. A Guide to the World's Fresh Water Resources, Oxford University Press, 473 pp, 1993.

Kadıoğlu, M., Van Gölündeki Su Seviye Yükselmesinin Meteorolojik Faktörler ile olan İlgisi, Lake Van Water Level Rise Symposium, T.C. Van Valiliği, 21-39 pp (in Turkish), 1995.

Kempe, S., Khoo, F., and Gürleyik, Y., Hydrography of Lake Van and Its Drainage Area. pp. 30-45 in the Geology of Lake Van, edited by Degen and Kurtman, The Mineral Research and Exploration Institute of Turkey, Rep. 169, 1978.

Ölçgen, A. Ş., Van Gölü Taşkýn Deşarj Tüneli Hidroelektrik Santralleri Projesi, Unpublished Report, 8 p (In Turkish), 1995.

Sieger, R., Die Schwankungen der hocharmenisehen Seen Seit 1880 im Vergleich mit einigen Verwandten Erscheinungen. Mitt. K.K. Geogr. Ges., 95-1155, 1888.

Wong, H. K., and Finckh, P., Shallow structures in Lake Van, pp. 20-27, in the Geology of Lake Van, Ed. Degen and Kurtman, The Mineral Research and Exploration Institute of Turkey, Rep. 169, 1978. 